\title{
Annual audit of neonatal morbidity in preterm infants
}

\author{
R W I Cooke
}

\begin{abstract}
Annual odds ratios, standardised for known confounding variables, were used to examine trends in major neonatal morbidities among 3220 preterm infants of less than 35 weeks' gestation admitted to a regional referral centre between 1980 and 1991. Despite improved survival, the risk of major cerebral haemorrhage, ventriculoperitoneal shunt insertion, and necrotising enterocolitis was unchanged. A recent reduction in risk of pneumothorax and persistence of the arterial duct was noted. An increased risk for chronic lung disease over time could be accounted for by increased survival, although a similar increase in risk for infection remained unexplained.
\end{abstract}

(Arch Dis Child 1992; 67:1174-6)

Medical audit aims to examine critically the structure, process, and outcome of medical care. In the field of neonatal intensive care,

Table 1 Definitions of descriptive and outcome variables used in the analyses

\begin{tabular}{|c|c|}
\hline \multicolumn{2}{|l|}{ Descriptive variables: } \\
\hline Birth weight & Birth weight in grams \\
\hline Gestation & Gestational age in completed weeks \\
\hline & Male/female \\
\hline Multiple pregnancy & Yes/no \\
\hline Mode of delivery & Vaginal/caesarean section \\
\hline Place of birth & Inborn/outborn \\
\hline \multicolumn{2}{|l|}{ Outcome variables: } \\
\hline Survival & Survival to discharge from unit \\
\hline Parenchymal haemorrhage & $\begin{array}{l}\text { Ultrasound scan evidence of parenchymal haemorrhage or } \\
\text { infarction }\end{array}$ \\
\hline BPD & $\begin{array}{l}\text { Oxygen dependency at } 28 \text { days with radiographic changes in } \\
\text { previously ventilated infant }\end{array}$ \\
\hline Ventriculoperitoneal shunt & $\begin{array}{l}\text { Treament of hydrocephaly by insertion of ventriculoperitoneal } \\
\text { or atrial shunt }\end{array}$ \\
\hline Pneumothroax & Pneumothorax treated by thoracocentesis \\
\hline Persistent ductus arteriosus & $\begin{array}{l}\text { Clinical diagnosis of ductal shunt which resulted in change in } \\
\text { management }\end{array}$ \\
\hline Septicaemia & Positive blood culture \\
\hline Necrotising enterocolitis & $\begin{array}{l}\text { Clinical diagnosis supported by radiographic, surgical, or } \\
\text { necropsy findings }\end{array}$ \\
\hline
\end{tabular}

Table 2 Descriptive variables that significantly changed over the study period

\begin{tabular}{|c|c|c|c|c|c|c|c|c|c|c|c|c|}
\hline & 1980 & 1981 & 1982 & 1983 & 1984 & 1985 & 1986 & 1987 & 1988 & 1989 & 1990 & 1991 \\
\hline $\begin{array}{l}\text { Outborn } \\
\text { Inborn } \\
(\%)\end{array}$ & $\begin{array}{c}78 \\
147 \\
(65)\end{array}$ & $\begin{array}{c}86 \\
183 \\
(68)\end{array}$ & $\begin{array}{c}94 \\
195 \\
(67)\end{array}$ & $\begin{array}{c}85 \\
234 \\
(73)\end{array}$ & $\begin{array}{r}76 \\
205 \\
(73) \\
\chi^{2} \text { for } t r\end{array}$ & $\begin{array}{c}81 \\
204 \\
(71) \\
\text { rend, } 7\end{array}$ & $\begin{array}{c}77 \\
207 \\
(73) \\
55, p=0\end{array}$ & $\begin{array}{c}88 \\
183 \\
(67) \\
\cdot 006\end{array}$ & $\begin{array}{c}58 \\
161 \\
(73)\end{array}$ & $\begin{array}{c}73 \\
189 \\
(72)\end{array}$ & $\begin{array}{c}65 \\
208 \\
(76)\end{array}$ & $\begin{array}{c}62 \\
181 \\
(74)\end{array}$ \\
\hline $\begin{array}{l}\text { Vaginal } \\
\text { delivery } \\
\text { Caesarean }\end{array}$ & 155 & 164 & 178 & 191 & 140 & 149 & 128 & 154 & 123 & 125 & 145 & 145 \\
\hline $\begin{array}{l}\text { section } \\
(\%)\end{array}$ & $\begin{array}{c}70 \\
(31)\end{array}$ & $\begin{array}{l}105 \\
(39)\end{array}$ & $\begin{array}{l}111 \\
(38)\end{array}$ & $\begin{array}{c}127 \\
(40)\end{array}$ & $\begin{array}{c}141 \\
(50) \\
\chi^{2} \text { for } t r\end{array}$ & $\begin{array}{c}136 \\
(48) \\
\text { end, } 13\end{array}$ & $\begin{array}{c}156 \\
(55) \\
3 \cdot 9, p=0\end{array}$ & $\begin{array}{c}117 \\
(43) \\
0.0002\end{array}$ & $\begin{array}{c}96 \\
(44)\end{array}$ & $\begin{array}{l}137 \\
(52)\end{array}$ & $\begin{array}{l}128 \\
(47)\end{array}$ & $\begin{array}{r}98 \\
(40)\end{array}$ \\
\hline $\begin{array}{c}\text { Gestation } \\
<28 \\
28-31 \\
32-34\end{array}$ & $\begin{array}{r}\text { eks) } \\
44 \\
87 \\
94\end{array}$ & $\begin{array}{r}59 \\
108 \\
102\end{array}$ & $\begin{array}{r}52 \\
108 \\
129\end{array}$ & $\begin{array}{r}63 \\
120 \\
136\end{array}$ & $\begin{array}{r}46 \\
120 \\
115\end{array}$ & $\begin{array}{r}54 \\
127 \\
107\end{array}$ & $\begin{array}{r}58 \\
144 \\
82\end{array}$ & $\begin{array}{r}60 \\
117 \\
94\end{array}$ & $\begin{array}{l}54 \\
81 \\
84\end{array}$ & $\begin{array}{r}57 \\
106 \\
99\end{array}$ & $\begin{array}{r}55 \\
101 \\
117\end{array}$ & $\begin{array}{l}59 \\
97 \\
87\end{array}$ \\
\hline
\end{tabular}

while structure and process are relatively easy to assess, it is often difficult to interpret the significance of observed differences in outcome between centres or over time. Data concerning the outcome of neonatal intensive care, by the nature of the specialty, are largely derived from referral centres, whose patient populations are subject to selection biases. Outcome in terms of survival and neonatal morbidity are well known to be affected by variables such as birth weight, gestation, sex, multiple pregnancy, mode of delivery, and place of birth. Differences in outcome between centres or from year to year in a single centre may be due to changes in population variables such as these, rather than to any response to medical intervention or management. Similarly, where morbidity is contingent upon neonatal survival, changes in survival alone may alter the prevalence of morbidity. In order to be able to interpret changes in neonatal morbidity in preterm infants over time in a single referral centre, annual trends have been examined after standardisation for known confounding variables and the effect of improved survival.

\section{Patients and methods}

All infants of less than 35 weeks' gestation admitted to the Mersey Regional Intensive and Special Care Unit between 1 January 1980 and 31 December 1991 were included in the study. By using the admission registers, case records, cranial ultrasound records, and microfilmed intensive care sheets the year of birth and descriptive and outcome variables were obtained for each infant (table 1). The descriptive variables were cross tabulated with the year of birth to examine for changes in the nature of the patient population over the 12 year period. The same variables were then similarly compared with the outcome variables to see which might act as confounding variables when trends in annual prevalence of the outcomes was examined. Each outcome variable was then entered into a logistic regression analysis as the dependent variable with each year and the identified confounding variables as the independent variables. From the analyses, the odds ratio and its $95 \%$ confidence interval for the risk of each outcome for every year compared with 1980, and standardised for the other significantly related variables, was obtained. For outcomes where the odds ratio significantly changed over the period studied, a further analysis was performed including death and/or that outcome 
Table 3 Outcome variables whose incidence was related to the descriptive variables on cross tabulation

\begin{tabular}{|c|c|c|c|c|c|c|c|c|}
\hline & Survival & $\begin{array}{l}\text { Parenchymal } \\
\text { haemorrhage }\end{array}$ & $\begin{array}{l}\text { Ventriculo- } \\
\text { peritoneal shunt }\end{array}$ & $B P D$ & Pneumothorax & $\begin{array}{l}\text { Persistent } \\
\text { ductus } \\
\text { arteriosus }\end{array}$ & Septicaemia & $\begin{array}{l}\text { Necrotising } \\
\text { enterocolitis }\end{array}$ \\
\hline $\begin{array}{l}\text { Multiple } \\
\text { Inborn } \\
\text { Sex } \\
\text { Caesarean }\end{array}$ & $\begin{array}{c}0.74 \\
<0.001 \\
0.01\end{array}$ & $\begin{array}{c}0.10 \\
<0.001 \\
0.93\end{array}$ & $\begin{array}{c}0.26 \\
<0.001 \\
0.04\end{array}$ & $\begin{array}{c}0.04 \\
<0.001 \\
0.31\end{array}$ & $\begin{array}{c}0.47 \\
<0.001 \\
0.14\end{array}$ & $\begin{array}{c}0.79 \\
<0.001 \\
0.03\end{array}$ & $\begin{array}{c}0.12 \\
<0.001 \\
0.63\end{array}$ & $\begin{array}{c}0.97 \\
<0.001 \\
0.39\end{array}$ \\
\hline $\begin{array}{l}\text { section } \\
\text { Gestation } \\
\text { Birth weight }\end{array}$ & $\begin{array}{l}<0.001 \\
<0.001 \\
<0.001\end{array}$ & $\begin{array}{r}0.001 \\
<0.001 \\
<0.001\end{array}$ & $\begin{array}{c}0.75 \\
<0.001 \\
<0.001\end{array}$ & $\begin{array}{c}0.37 \\
<0.001 \\
<0.001\end{array}$ & $\begin{array}{c}0.40 \\
<0.001 \\
<0.001\end{array}$ & $\begin{array}{c}0.43 \\
<0.001 \\
<0.001\end{array}$ & $\begin{array}{c}0.83 \\
<0.001 \\
<0.001\end{array}$ & $\begin{array}{c}0.96 \\
<0.001 \\
<0.001\end{array}$ \\
\hline
\end{tabular}

Exact probabilities are used except where shown.

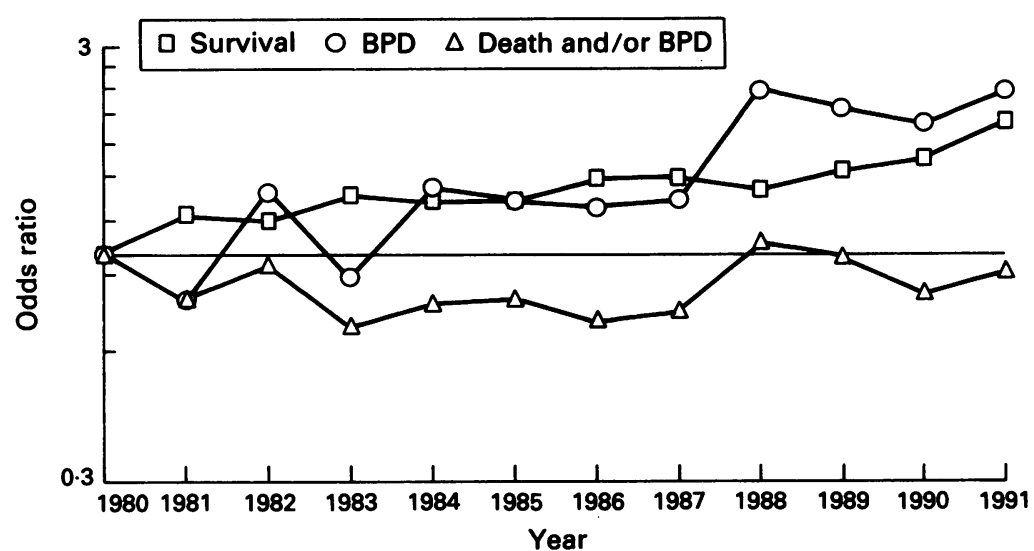

Figure 1 Annual odds ratios for survival, BPD, and death and/or BPD; $95 \%$ confidence intervals are omitted for clarity.

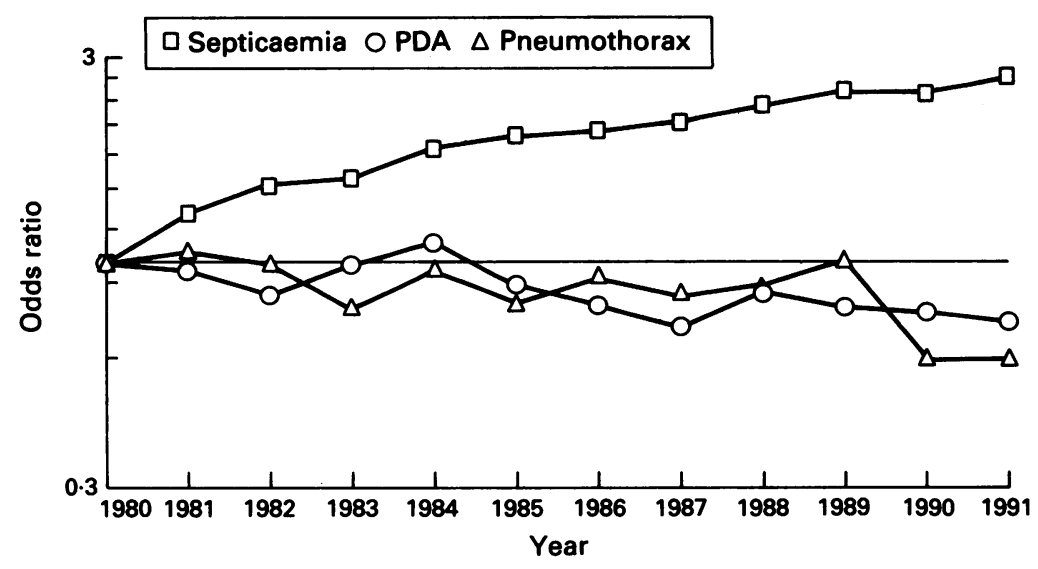

Figure 2 Annual odds ratios for septicaemia, persistent ductus arteriosus (PDA), and pneumothorax; $95 \%$ confidence intervals have been omitted for clarity.

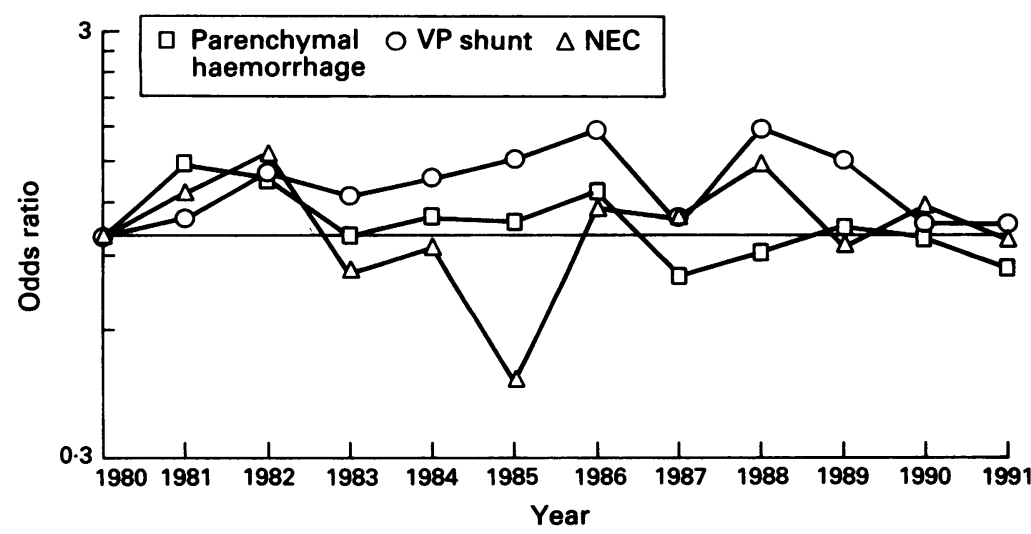

Figure 3 Annual odds ratios for parenchymal haemorrhage, ventriculoperitoneal (VP) shunt, and necrotising enterocolitis (NEC); $95 \%$ confidence intervals have been omitted for clarity. as an independent variable to correct for the effect of improved survival, and the resulting odds ratios re-examined.

The $\chi^{2}$ test and $\chi^{2}$ test for trend were used to test for significance in the cross tabulations, and the logistic regression was performed using the Logit option of the Probit program in SPSS-X Release $3 \cdot 1^{1}$

\section{Results}

A total of 3220 infants were included in the study. Data were complete apart from cranial ultrasound scans that were not performed on 431 infants who were either larger well infants or those with lethal malformations. Of the descriptive variables, lower gestation, and increased frequency of caesarean section and inborn delivery were seen in more recent years (table 2). Outcomes were significantly associated with gestation, birth weight, inborn delivery, sex, and birth by caesarean section (table 3). The odds ratios for survival, bronchopulmonary dysplasia (BPD) and septicaemia increased for more recent years (figs 1 , 2 , and tables 4, 5). A trend to reduction of risk for pneumothorax and persistent ductus arteriosus was seen (fig 2, table 5), but not for parenchymal cerebral haemorrhage, insertion of a ventriculoperitoneal shunt, or necrotising enterocolitis (fig 3).

The effect of increased survival in more recent years was taken into account by calculating the odds ratios for 'death and/or BPD' for each year. In no year did these significantly exceed 1 (fig 1 , table 4 ). A similar calculation for septicaemia showed a residual trend to increased risk in recent years.

\section{Discussion}

Using a logistic regression technique, it has been possible to examine trends in survival and neonatal morbidity over a 12 year period after standardising for known confounding variables. Despite the marked improvement in survival in recent years, morbidities such as major cerebral haemorrhage and infarction, shunted hydrocephalus, and necrotising enterocolitis are as likely to occur now as in $\mathbf{1 9 8 0}$. The occurrence of persistent ductus arteriosus and pneumothorax have also remained substantially unchanged except in the last year or two when both have been significantly less likely to occur. The greatest improvements in the chance of survival have also been in the last two years. A possible explanation for these findings is the introduction of surfactant treat- 
ment for all infants likely to benefit from it. Reduction of persistent ductus arteriosus and pneumothorax as well as improved survival have been noted as important effects of surfactant treatment. ${ }^{2}$ There has been a signifi-

Table 4 Annual odds ratios (with 95\% confidence intervals) for survival, BPD, and death and/or BPD

\begin{tabular}{llll}
\hline Year & Survival & $B P D$ & Death and/or $B P D$ \\
\hline 1981 & $1.22(0.96$ to 1.55$)$ & $0.78(0.48$ to 1.27$)$ & $0.78(0.60$ to 0.98$)$ \\
1982 & $1.19(0.94$ to 1.52$)$ & $1.39(0.92$ to 2.10$)$ & $0.94(0.73$ to 1.19$)$ \\
1983 & $1.36(1.08$ to 1.75$)$ & $0.88(0.56$ to 1.41$)$ & $0.68(0.53$ to 0.87$)$ \\
1984 & $1.31(1.02$ to 1.68$)$ & $1.41(0.94$ to 2.13$)$ & $0.77(0.60$ to 1.98$)$ \\
1985 & $1.32(1.04$ to 1.70$)$ & $1.32(0.87$ to 2.00$)$ & $0.79(0.62$ to 0.01$)$ \\
1986 & $1.48(1.15$ to 1.89$)$ & $1.28(0.84$ to 1.94$)$ & $0.70(0.55$ to 1.90$)$ \\
1987 & $1.50(1.18$ to 1.94$)$ & $1.33(0.89$ to 2.01$)$ & $0.74(0.58$ to 1.95$)$ \\
1988 & $1.40(1.09$ to 1.84$)$ & $2.38(1.61$ to 3.49$)$ & $1.06(0.82$ to 1.36$)$ \\
1989 & $1.55(1.20$ to 2.01$)$ & $2.16(1.47$ to 3.18$)$ & $0.98(0.77$ to 1.26$)$ \\
1990 & $1.65(1.27$ to 2.15$)$ & $1.99(1.35$ to 2.94$)$ & $0.81(0.63$ to 1.04$)$ \\
1991 & $2.08(1.57$ to 2.76$)$ & $2.37(1.61$ to 3.48$)$ & $0.91(0.71$ to 1.18$)$ \\
\hline
\end{tabular}

Table 5 Annual odds ratios (with 95\% confidence intervals) for septicaemia, persistent ductus arteriosus, and pneumothorax

\begin{tabular}{llll}
\hline Year & Septicaemia & $\begin{array}{l}\text { Persistent ductus } \\
\text { arteriosus }\end{array}$ & Pneumothorax \\
\hline 1981 & $1.30(0.97$ to 1.74$)$ & $0.96(0.76$ to 1.22$)$ & $1.06(0.82$ to 1.37$)$ \\
1982 & $1.52(1.15$ to 2.01$)$ & $0.84(0.65$ to 1.07$)$ & $0.99(0.82$ to 1.37$)$ \\
1983 & $1.57(1.19$ to 2.07$)$ & $0.99(0.78$ to 1.25$)$ & $0.78(0.60$ to 1.03$)$ \\
1984 & $1.84(1.39$ to 2.42$)$ & $1.11(0.88$ to 1.40$)$ & $0.96(0.74$ to 1.25$)$ \\
1985 & $1.96(1.49$ to 2.58$)$ & $0.88 \cdot(0.69$ to 1.13$)$ & $0.80(0.61$ to 1.06$)$ \\
1986 & $2.01(1.53$ to 2.64$)$ & $0.79(0.62$ to 1.03$)$ & $0.92(0.71$ to 1.19$)$ \\
1987 & $2.11(1.61$ to 2.78$)$ & $0.70(0.52$ to 0.89$)$ & $0.83(0.63$ to 1.08$)$ \\
1988 & $2.29(1.73$ to 3.03$)$ & $0.85(0.64$ to 1.11$)$ & $0.88(0.67$ to 1.17$)$ \\
1989 & $2.48(1.98$ to 3.25$)$ & $0.78(0.60$ to 1.01$)$ & $1.01(0.78$ to 1.31$)$ \\
1990 & $2.45(2.00$ to 3.57$)$ & $0.76(0.58$ to 0.99$)$ & $0.85(0.64$ to 1.11$)$ \\
1991 & $2.66(2.00$ to 3.57$)$ & $0.72(0.54$ to 0.94$)$ & $0.59(0.42$ to 0.82$)$ \\
\hline
\end{tabular}

cant increase in the risk of BPD. While it has been possible to show that specific factors may be responsible for this increase in high risk subgroups, ${ }^{3}$ the overall trend to higher risk for developing BPD may simply be related to increased survival of very preterm infants. When the risk of death and/or BPD is examined, the odds ratio for this outcome does not significantly exceed 1 in any year, suggesting that most of the increased occurrence of BPD is indeed related to improved survival. The risk of septicaemia has continued to increase over the study period, and could also be related to improved survival of high risk infants. After standardising for survival in a similar way, however, the increasing risk for septicaemia over the years persisted. It may be that a variable such as increased duration of stay in the unit is more important.

The use of an audit method as described can be an ongoing process, and may identify real changes in morbidity over time in a large referral centre, allowing assessment of the effect of management policies, and the highlighting of problems requiring further study.

1 SPSS Inc. SPSS-X users guide. 3rd Ed. Chicago:SPSS Inc, 1988.

2 Soll RF. Synthetic surfactant therapy for RDS. In: Chalmers I, ed. Oxford database of perinatal trials. Version 1.2. Disk issue 6. Autumn 1991. Record 5252.

3 Cooke RWI. Factors associated with chronic lung disease in preterm infants. Arch Dis Child 1991;66:776-9. 